\title{
Promoting quality and equity: An exploratory case study of a primary school in England exploring barriers and facilitators in implementing the Dynamic Approach to school improvement
}

\author{
Panayiotis Antoniou \& Julia Griaznova
}

Faculty of Education, University of Cambridge

\begin{abstract}
A number of studies have been conducted to identify the impact of the Dynamic Approach to School Improvement (DASI) on student outcomes, using mainly quantitative and experimental designs. However, few studies explored the impact of DASI in schools facing challenging circumstances using qualitative methods. This in turn restricts our ability to provide in-depth and detailed explanations of how, why and under which conditions DASI works in improving student outcomes in socially disadvantaged schools. This study provides an in-depth understanding of the teachers' perspectives of the facilitators and barriers they encountered while implementing DASI in a primary school in England with a relatively high percentage of socially disadvantaged students. Data were gathered from teachers using semistructured interviews at the beginning, during and the end of the intervention. The results of the study highlight important changes in a number of elements related with teacher, school and DASI characteristics.
\end{abstract}

Keywords: DASI; equity; schools in socially disadvantaged areas; school evaluation; school improvement; teacher perspectives;

\section{Highlights:}

- DASI was implemented to an underprivileged school in England

- Teachers perspectives were explored via in depth-interviews

- Facilitators and barriers were identified at various levels

- The important role of the Research and Advisory Team was stressed

\section{Introduction}

During the last decades the education system in England is defined by the recurring attempts for school reform. The era of school reform and improvement has descended upon many of the industrialized nations, and research in traditions of educational effectiveness and school 
improvement has thrived and received increasing attention in the last years (Coe, 2009). Yet, due to the divergent focus of research in the fields of educational effectiveness and school improvement there is a gap between school reform theory and practice. As such, many schools are caught in the cycle of school improvement fads, seeking to improve teaching and increase student outcomes, but with little notable progress in either as they move from one initiative to the next (Borman, Hewes, Overman, \& Brown, 2003). Scholars attribute the failure of many school improvement initiatives to the lack of linkages between the fields of educational effectiveness, which focuses on theory, and the tradition of school improvement which is concerned with practice (Creemers, Kyriakides, \& Sammons, 2010).

Until recently there has been relatively little interaction between School Effectiveness and School Improvement research and as such two distinct research traditions have developed (Chapman et al., 2012; Creemers, \& Kyriakides, 2015). School effectiveness considers the outcomes of schooling and how various factors influence students' educational attainment (Fidler, 2001). Alternatively, school improvement research is focused on the process of change, and the ways in which the quality of schools can be improved (Hallinger \& Heck, 2011). Scholars conducting research in the area of school improvement are concerned with developing strategies to be implemented by practitioners in enhancing aspects of the school and education process (Hopkins, Ainscow, \& West, 1994). Although effort has been made to bridge the two traditions, significant differences exist in the type of research being conducted whereas meaningful links between educational effectiveness and school improvement are rare (Chapman et al., 2015).

Despite their differences in theoretical orientation and methodology, school effectiveness and school improvement have complementary strengths and weaknesses (Scheerens, 2016). As such, it has been suggested that for these fields to progress further, collaboration is not only desirable, but also a necessary precondition (Scheerens, 2016; 
Creemers, \& Kyriakides, 2008). While a number of scholars and practitioners have engaged in improvement projects that combine aspects of both research traditions, Hopkins, Ainscow, and West, (1994) suggest that greater consolidation between these paradigms can only be reached through the development of theoretical frameworks. In this perspective, Creemers and Kyriakides (2012), combining major elements of school improvement and educational effectiveness research, have developed the Dynamic Approach to School Improvement (DASI).

\section{The impact of DASI on quality and equity}

A number of studies have been conducted over the past decade to identify the impact on student outcomes and to provide empirical support to the key characteristics of DASI (e.g., Creemers \& Kyriakides, 2012; 2010b; Heck \& Moriyama, 2010). However, from a methodological perspective, while the existing research on DASI utilizes advance quantitative and experimental methods, qualitative designs have only rarely been used, which in turn restricts our ability to provide in-depth and detailed explanations of how, why and under which conditions DASI works in improving student outcomes. In this perspective, although the effectiveness of DASI has been well established in the literature (Creemers \& Kyriakides, 2015), there is an urgent need to explore teachers' perspectives, attitudes and perceptions on implementing the DASI framework.

Lawless and Pellegrino (2007) in their review argue that even though during the last years a number of school improvement initiatives have been developed and implemented, our understanding of how exactly these programs are perceived by teachers and which elements could justify their effectiveness is still limited. In addition, Wayne et al. (2008) argued that research to this end is rather weak and has not addressed practical issues which could facilitate the development and successful implementation of school improvement initiatives. 
It is important to understand the challenges and facilitators that teachers encounter in the course of school reform initiatives in greater depth (Kirkpatrick \& Johnson, 2014; Antoniou et al., 2015). This becomes ever more significant considering that a number of studies across a wide range of countries have shown that the influence of teachers on school improvement efforts and results is of great importance (Chapman et al., 2015). Greater understanding of teacher perspectives on and experiences with school reform is needed to enable school leaders and consultants to provide teaching staff with appropriate and useful support. School improvement projects could benefit from efforts to improve the process at the implementation level, thus increasing the likelihood of success and prospective sustainability of the effects not only of the DASI but also of other similar school improvement initiatives.

This is especially significant for schools in socially disadvantaged areas facing particularly challenging circumstances. The educational reform agenda internationally acknowledge the importance of equity and the provision of equal educational opportunities for all children, along with a renewed interest in improving schools in underprivileged areas (Chapman \& Harris, 2004; Muijs et al., 2004). While some argue that the 1990s expansion of school improvement and accountability reforms improved student achievement, others contend that these policies widened achievement gaps between advantaged and disadvantaged students (Strand, 2014). As Gray (2000, p. 33) argues, “we don’t really know how much more difficult it is for schools serving disadvantaged communities to improve because much of the improvement research has ignored this dimension'". Given that early effectiveness studies were concerned with identifying ways to help schools in disadvantaged areas to improve their learning outcomes, it is important to find out whether DASI can help schools in socially disadvantaged areas to improve their effectiveness. 


\section{The School Improvement intervention based on the Dynamic Approach}

The Dynamic Approach to School Improvement (DASI) is a theory-driven and evidencebased approach designed to improve educational practice in schools and ultimately student outcomes (Creemers \& Kyriakides, 2012). The DASI framework stands apart from other school improvement models in that it is informed by findings from both educational effectiveness and school improvement research.

The theoretical framework of DASI is based on the Dynamic Model of EER (Creemers \& Kyriakides, 2008). Particularly, at the school level the model refers to four major factors. The first factor is the school's policy on teaching and the activities undertaken with the goal of improving teaching (Creemers, Kyriakides \& Antoniou, 2013a). This factor is further broken down into quantity of teaching, quality of teaching and provision of learning opportunities. The second factor is directly related to the first, and relates to the evaluation of the policy on teaching (Creemers \& Kyriakides, 2010b). The third factor refers to school policy and the activities undertaken to improve school's learning environment. This in turn consists of five elements: partnership policy, provision of resources, collaboration between teachers, student behaviour outside the classroom, and values favouring learning. The fourth factor is concerned with the evaluation of the policy on school's learning environment (Creemers \& Kyriakides, 2012).

In relation to measuring those factors, one of the key aspects of DASI which distinguishes it from other models, is the incorporation of five measurement dimensions, through which the factors are defined and measured (Kyriakides \& Creemers, 2008). These dimensions refer to the issues of frequency, focus, stage, quality and differentiation. All dimensions, with the exception of frequency, provide qualitative information regarding the factors residing at the classroom, school and system levels (Creemers \& Kyriakides, 2010a). 
DASI also suggests and describes the methodology and the basic phases for its implementation in school settings. The first step is to present the framework to the school staff and based on discussion and guided critical reflection to reach an agreement on the overarching goals of the school improvement initiative which needs to be directly related with improvements in student learning outcomes. Once the teaching staff has been familiarised with the framework, the next step is the initial evaluation, i.e., collect data on student achievement and the functioning of the school factors, via student test and teacher questionnaires respectively. Following the initial evaluation of the functioning of school factors, the school staff, with the assistance and guidance of the Research and Advisory Team, discuss the results and decide their improvement area, e.g., improving the school policy on quality of teaching (Creemers and Kyriakides, 2010a; Kyriakides et al., 2009).

Having chosen their improvement priority, in subsequent meetings and with the assistance of the Research and Advisory Team, the school management team and teaching staff develop their school policy and action plans for improvement. During this stage the Research and Advisory Team is expected to regularly visit the school and is actively engaged in helping teachers develop and implement their action plans providing suggestions based on research evidence and literature on the selected area for improvement (Creemers, Kyriakides \& Antoniou, 2013b). In addition, in collaboration with the school management team and teaching staff, formative evaluation procedures are being established, based on regular meetings, critical structured reflection and discussion to informally assess the progress made and suggest necessary actions whenever appropriate. This procedure allows schools to evaluate and improve their policy and guidelines and also teachers to improve their action plans, assuring that any issues or inconsistencies that were identified, were addressed in a timely manner. By the end of the school year, the functioning of the school factors and student achievement in mathematics are measured to evaluate the impact of DASI on 
improving learning outcomes and the functioning of school factors (Creemers \& Kyriakides, 2012).

\section{Research Aims}

The study presented in this paper is an exploratory case study aiming to provide an in-depth understanding of the teachers' perspectives of implementing DASI in a primary school in England with a relatively high percentage of socially disadvantaged students during the academic year 2015-2016. Specifically, we were interested to explore the process of school improvement and to identify types of challenges and facilitators experienced by teachers during their efforts to improve both the quality and equity of teaching. In addition, the study reported here explores how and under which conditions DASI can have an impact on student achievement in socially disadvantaged areas, so as to promote not only quality but also equity in education.

\section{Personal Background and interest for the study}

Our interest in this particular study stems from our own background in education and our previous efforts and concerns to improve the quality of education. One of us has been researching and teaching in higher education in the fields of school leadership, school effectiveness, school evaluation and improvement and who has been involved in several studies exploring the impact of DASI on student academic outcomes. The other one is a registered early childhood educator and a licenced teacher in Ontario, Canada, currently studying for her Doctorate in the area of school effectiveness and school improvement in England. 
Our focus has consistently been on school settings, and in the past years we had numerous opportunities to visit, train and work in a number of schools. As such we have had the chance to observe and participate in a number of school improvement initiatives. While we wholeheartedly supported the spirit of school improvement endeavours, our practical experience with this concept was sometimes disappointing. We often noticed a recurring lack of theory and evidence based practice in the improvement approaches being implemented, and indication of improvement was difficult to discern upon the conclusion of such initiatives. Furthermore, we were rather disappointed to see staff engagement levels steadily drop over the life span of improvement initiatives, thus leaving many interventions to fizzle out. As Sprinthall et al., (1996) argue, theory no matter how carefully stated will have little utility for teacher development if the connections to performance cannot be determined. In particular, in terms of empirical justification, there is little solid evidence that supports the view that any school improvement initiative result in superior teaching practices and improved student outcomes (Cornford, 2002; Creemers, et al., 2012). Although there is a large body of literature on school improvement and teacher professional development approaches, surprisingly little attention has been paid to the actual content, processes and impact of such approaches (Garet et al., 2001). In this perspective, we both believe that it is important to gain a better, in-depth understanding of the conditions under which school improvement initiatives prove to be effective in relation to student outcomes, by exploring teachers' perspectives on barriers and facilitators of school improvement.

\section{Research Methods}

The methodology for the data collection and analysis was based on the Symbolic Interaction Theory (Blumer, 1969). Under this theory, human beings are viewed as social agents who are influenced by external factors (e.g., school policies, school leadership) but who are also 
capable of maintaining distance and able to initiate individual action and meaning through interpretive processes. The basic premise is that human behaviour is largely a function of how situations are perceived and interpreted. Consistent with symbolic interaction theory, no concepts from the literature were employed a priori to direct data collection.

\subsection{Sample}

Data were collected from an English primary school in the area of Cambridgeshire which during the school year 2015-2016 participated in an experimental study investigating the impact of DASI on student achievement in Mathematics. The study involved a number of schools from four different countries, i.e., England, Cyprus, Greece and Ireland. The schools in each country were randomly allocated into two groups. The control group, receiving only initial and final evaluation results on the functioning of school effectiveness factors, and the experimental group, which fully implemented DASI. The particular school was selected for this case study due to the relatively high percentage of students from socially underprivileged families. In addition, the analysis of the student tests revealed that the school managed to improve student achievement in Mathematics during the year of implementing DASI, by improving its policy and practice on quality of teaching. Data were gathered from primary school teachers $(n=16)$. Involvement in the study was voluntary. Our teacher sample was predominately female. Particularly, our study sample consisted of two male and fourteen female primary school teachers. The average age of teachers was thirty-four and the average number of years in teaching was twelve. The educational level of study participants ranged from PGCE, Bachelor to Masters Degrees.

\subsection{Data collection}

Semi-structured interviews were employed for the data collection. Semi-structured interviews are particularly powerful primary sources of data collection since they have the potential to 
elaborate on a single topic in-depth and increase the probability of gathering a broad range of relevant data about the phenomenon under investigation (Teddlie \& Sammons, 2010). The interviews took place in two different phases: during and by the end of the school year during which the school implemented DASI and they were based on several issues. Teachers were asked to provide detailed descriptions of the characteristics and processes that have facilitated the implementation of DASI and had a positive impact on their school / classroom teaching. In addition, they were asked to explain how effective were these characteristics and in which aspects they have had an impact. Likewise, teachers were also asked to describe the barriers and constraints they experienced in their efforts to implement DASI during the school year. Our main purpose was to identify any changes in teacher perceptions during the year in relation to facilitators and obstacles to school improvement and try to explain those changes. The questions used in the interviews in both phases were pilot tested in four teacher interviews taking place before each main data collection phase. The results from the pilot interviews led to a better clarification of the concepts mentioned in some questions.

\subsection{Data analysis}

The interviews were recorded and transcribed for analysis. In cases where clarifications were required, the respondents were contacted through telephone. We made use of the NVivo software to analyse the data. The data analysis was based on the constant comparative method to examine new and old data for discrepancies (Creswell \& Plano Clark, 2011). Particularly, the data were coded according to guidelines for inductive-exploratory research and comparative analysis (Glaser, 1965). This form of analysis requires a comparison of each new element coded previously with emergent categories and subcategories. We also used an open, axial and selective coding technique to analyze the interviews and develop conceptual categories (Creswell, 2012). Through open coding, we examined the transcripts for similarities and separate data into initial broad categories. We followed this up with axial 
coding during which we re-examined the previously developed categories to establish interand intra-category links and combine data in new ways (Tashakkori \& Teddlie, 1998). Thus, the development of the conceptual framework of barriers and facilitators of implementing the DASI framework was grounded to the data, with the data leading to the development of the theory (Glaser \& Strauss, 1967).

To enhance the creditability of our findings we engaged in member checks through the process of data analysis wherein we asked participants to review the broad themes we identified and confirm that these were accurate and representative of their experience. We also practiced reflexivity and engaged another peer to debrief our work and check for personal bias in our interpretation of the data, assessing the consistency of the themes (Creswell \& Plano Clark, 2011).

\section{Research findings}

The results of the study revealed several key components facilitating or constraining the effective implementation of the DASI, situated at different levels. Particularly, our teacher sample has identified a number of facilitators and barriers located at the (a) teacher level, i.e., related with teacher characteristics, (b) school level, i.e., related with school's characteristics and processes, and finally (c) the DASI level, related with some of the basic characteristics of this particular school improvement approach, all of which are elaborated below:

\subsection{Facilitators of DASI effective implementation}

\section{A) Facilitators at the teacher level:}

1) Improving teacher efficacy: 
Teachers have identified that efficacy was an important facilitator to effectively implement DASI at their school. What is perhaps more interesting to note is that teachers were reluctant to discuss issues related with improving the learning of students from underprivileged families at the beginning, since they considered that they couldn't have any significant effect on their outcomes and they attributed their failure to external factors.

At the start I wasn't that sure I could or even I wanted to improve... But then, once you presented and we discussed the material, the previous findings... I believed I could do it, I believed that I had what it takes to make it and this has made a huge contribution to the extent to which I decided to engage with the program.

(Teacher 4)

During the course of time and with the guidance of the Research and Advisory Team the teachers came to realise that the program requirements were feasible and that they could have an impact and that their role, especially in relation to those children, was crucial. As teachers noted:

..if it was something I felt I couldn't do or accomplish...[or] not related with practical issues and teaching skills...I wouldn't have taken the step to implement any of the activities in my action plan.

(Teacher 9)

An important factor was that involvement with DASI did not require anything that we wouldn't normally do as teachers... it made us realise that we could indeed have an impact especially on the underprivileged students...

(Teacher 15)

A number of studies have shown that teacher's efficacy does have an influence on the educator's effectiveness in the classroom (Kirkpatrick \& Johnson, 2014). In particular, high teacher efficacy has been correlated with quality teaching, and a healthy classroom environment (Pas, Bradshaw \& Hershfeldt, 2012). Moreover, teacher efficacy has been shown to be particularly important when it came to teachers working in schools serving 
students from a range of cultural and socio-economic contexts. As back as in 1984, Gibson and Dembo examined teacher's beliefs regarding their ability to impact the academic outcomes of children from low-SES families. They found that teachers who demonstrated low efficacy believed were not able to influence student outcomes due to external factors, whereas teachers with high efficacy believed that they had the capacity to make a difference. This is a key finding, since a teacher is unlikely to engage with the students from a range of backgrounds and engage effectively in school improvement initiatives, if they believe that their efforts will not have an impact.

\section{2) Improving teacher engagement:}

Teachers in our sample also supported that efficacy was highly correlated with their engagement levels and they believed that high efficacy corresponded to high work engagement in relation to the school improvement initiative. Although some teachers were initially not supportive of the school improvement initiative, they developed more positive perceptions once they realised that their role in the intervention was related with their everyday tasks and the expectations were feasible and realistic.

...engagement and commitment were necessary conditions. I felt that it was my duty to put the energy and effort needed to make this work, not for me, but for my students...especially those in real need. (Teacher 1)

I believe that if teachers really want to, they can make a huge difference in student outcomes, even for the less privileged ones. But to do so they need to be engaged and committed to the school mission, they need to embrace the vision and purpose of the school policy and improvement initiative.

(Teacher 7)

They also stressed the important role of the Research and Advisory Team and their colleagues' contribution in improving their engagement with DASI. As teachers emphasized: 
....and based on our discussions with the team, it was made obvious that some colleagues have benefited.

(Teacher 1)

...especially [name of teacher] was so positive and enthusiastic about the whole thing....that was when I actually started thinking that it could be a good policy for our school and that I could indeed improve my teaching skills in certain domains

(Teacher 11)

As Halbesleben (2010) argues, work engagement is desired in teachers because productivity and performance of highly engaged individuals is higher, which benefits the organization. On the other hand, disengaged employees lack motivation and place little effort into their jobs, lowering their productivity and success in the field (Hakanen, 2006). More importantly, engaged teachers are willing to expand their roles as necessary (Macey et al., 2009). Teacher engagement is the way educators perceive their work, and the energy and effort they put into their school ( $\mathrm{Gu} \&$ Day, 2013). Engaged teachers are "energetic, interested and enthusiastically involved in their work" (Kirkpatrick \& Johnson, 2014, p. 233). Highly engaged teachers positively impact their work environment in both direct and indirect ways in terms of student outcomes and the quality of school environment (National Center on Effective Secondary Schools, 1992). Gu and Day (2013) note that initially it is the educators' commitment to their profession and the desire to make a difference in the schools and the lives of the students which fosters high engagement. Yet, it is necessary to emphasise that engagement is not a stable factor, but one which fluctuations throughout a teacher's career and in response to the various factors within the school. In their study of second stage teacher engagement Kirkpatrick and Johnson (2014) found that teacher's engagement was influenced by their work context, specifically by "the levels of encouragement and challenge they experienced in their workplace" (p. 240). Recognition of engagement by leaders and peers in the school is an important facilitating factor of engagement, and without it, engagement levels will drop overtime. And that was exactly what the Research and Advisory 
Team managed to accomplish. On the other hand, teachers whose engagement is acknowledged and supported in the school, increase and sustain their level of engagement (Kirkpatrick, \& Johnson, 2014).

\section{B) Facilitators at the School level:}

\section{1) Supportive school leadership}

A common element among all teacher interviews was a clear reference to the important role of the school headteacher, as an important facilitator for the effective implementation of DASI. The school head was considered by teachers as one key factor for developing and implementing the school policy on quality of teaching, which was the focus of the school improvement initiative, in close collaboration with the Research and Advisory Team. That was accomplished directly, through one to one or group discussions, revision of action plans and classroom observations and indirectly through the designation of teacher and parents' roles in the well-functioning of the school both inside and outside classrooms and the publication of various documents in relation to school's policy on quality of teaching. As teachers argued:

He was coordinating the implementation of the school policy....documents, announcement, guidelines published by our school management team in relation to quality of teaching...

(Teacher 2)

... and then he was there for us, to support and... to discuss what kind of activities we have included in our action plans...

(Teacher 6)

He was actually monitoring and discussing with each one of us the number of visits we exchanged per term. He was also managing the school program, 
so as to allow us time for discussion with our colleagues. I believe that this and this alone was by far the best interaction we could have. (Teacher 14)

The headteacher was also considered by teachers as the one preparing the culture appropriate for DASI, during the very early stages, spending time on capacity-building and a culture of acceptance for the new initiative.

At the beginning of the year he [the headteacher] spent time reflecting and discussing with colleagues whether this was something we wanted and needed for our school...

(Teacher 16)

...he has, in a way, convinced us that there was value in DASI even before your first visit, that our students, especially those coming from underprivileged families would be benefited.

(Teacher 7)

This is consistent with previous research findings in which teachers indicated that strong and supportive leadership was a factor which aided the implementation of improvement initiatives and facilitated the success of school reform (Mendenhall et al., 2013). Many scholars discuss the importance of establishing effective school policies which may have an effect on improving student learning outcomes (Hattie, 2009; Reynolds et al., 2014). Schools are seen as the "basic unit of change and school educators (teachers and principals) are not only the agents, but also the initiators, designers, and directors of change efforts" (Smith \& O'Day, 1991, p. 235). Likewise Gu and Day (2013) reported that teachers responded to strong, receptive leaders and specified that support from the leadership team prompted them to stay engaged in improvement enterprises despite the challenges they faced. The authors also note that teachers perceived leader support to help counteract some of the obstacles that they encountered. Supportive leadership was also found to be a particularly important facilitating factor in schools facing challenging circumstances (Chapman \& Harris, 2004). The results of this study seem to provide support to the argument that teachers are more likely 
to perceive school improvement as a positive experience when school leaders are engaged and strongly support the improvement process.

\section{2) Promoting peer support and collaboration}

Peer support at the school level is another factor that teachers identified as facilitating their effective involvement in the DASI initiative. Teachers supported that they have more incentives to meet and collaborate as a result of their engagement with DASI.

...we were encouraged to discuss and even visit other teachers to observe their teaching. We have been encouraged to develop as learners who collaborate with one another to study teaching and its effects. (Teacher 5)

Collaborative networks among us were essential for improving our teaching and learning... this collaboration resulted in increasing our motivation and reflective behaviour...

(Teacher 13)

What is interesting to note is that teachers have identified that a big change they noticed was related with the focus of their discussions with peer. They acknowledged that DASI and particularly the Research and Advisory Team has directed their collaboration and discussions on issues which were directly related with student learning and the learning of students coming from underprivileged backgrounds, something which was in line with their school policy. As teachers argued:

I stretched out, discussed and tried new strategies of effective teaching because of the support the team provided...we were responsible for each other...I became a better teacher, I worked harder to find solutions, and I was anxious to share whatever I learned, how my students reacted, with others.

(Teacher 15)

....based on our discussions [with the Research and Advisory Team]... we were encouraged to share our teaching experiences, problems and suggestions...particularly in relation to those children.... makes me want to improve.

(Teacher 2) 
In line with this finding, Mendenhall et al., (2013) also found that collaboration among the peers within school greatly supported the success of school improvement initiatives. Networking and professional openness between teachers working in the same school is a key resource which supports teacher efficacy and work engagement (Hoy \& Hannum, 1997). With regards to school improvement initiatives, peer support and collaboration helped teachers to overcome barriers encountered in the process of change (Mendenhall et al., 2013). Collaboration between teachers supported the staff on both physical and psychological level and helped teachers to alleviate the emotional toll incurred in the process of change (Hakanen, Bakker \& Schaufeli, 2006).

\section{C) Facilitators at the DASI level:}

\section{1) Clarity of improvement objectives}

The majority of the teachers emphasized that an important element which contributed to their decision to engage effectively with DASI was the clarity of the objectives and the clear direction of the initiative, supported with empirical findings, i.e., evaluation of the functioning of effectiveness factors in their particular school. As teachers noted:

....made us think it is important to have a common sense of direction, a common and clear direction as a group on quality of teaching, which was also supported by the evaluation findings. That was really important since many times we forget what the real purpose of schooling actually is...this has never occurred with previous school improvement initiatives, and believe me I have been through many!

(Teacher 8)

I really valued the fact that the team [Research and Advisory Team] helped us make better sense of our job and our school improvement goals...enabled us to identify the importance of teaching for our students' lives, the importance of our actions in the classrooms... That was an excellent start for the whole year!

(Teacher 6) 
Several teachers stated that they felt as being motivated by the fact that the goals which they considered important and compelling were taken into consideration, during the initial evaluation phase and the initial discussions with the Research and Advisory Team.

The initial evaluation phase and the discussions we had on the findings made me think critically about our mission as teachers and more generally of the impact of our actions in the classroom...it was absolutely essential to have a clear direction from the very beginning.

(Teacher 10)

.... and the fact that we know where we were heading...it was clear what was the main purpose of the program... and with which we agreed at the very early stages based on our school's evaluation findings (Teacher 3)

DASI takes into account the importance of identifying specific needs and priorities for improvement of each school. This implies that, unlike most school improvement initiatives with a "one size fits all" orientation, the improvement focus varies according to the school needs. In order to identify these priorities, multiple evaluation data on the functioning of school factors should be collected and factors that need to be addressed and further developed should be identified. This is important as identifying specific practices fundamental to supporting student learning is at the heart of building an effective system for the professional training and development of teachers (Antoniou \& Kyriakides, 2011; 2013).

\section{2) The Role of the Research and Advisory Team}

A common element in all teacher interviews was the important role of the DASI Research and Advisory Team. The team played a significant role in all stages during the school year, from explaining the importance of the intervention based on a solid theoretical background to providing support and constructive feedback that facilitated the development and implementation of policy at the school. It was also made clear that the team gradually gained 
the respect and acceptance from more teachers in the school. The teachers found important a number of characteristics / roles of the Research and Advisory Team such as respect of the teachers' time and making feasible and realistic suggestions. As teachers noted:

The truth is that our time is extremely limited and we had our doubts about DASI at the start of the year.... with short meetings and clear and to the point discussions...more teachers decided to actively engage with the program

(Teacher 12)

It was important to that DASI also worked with our school management team and principal and not solely with teachers. This is important as finding time to do things is really an issue, especially in this school, but the members of the team were always conscious of that and respected our time.

(Teacher 14)

In addition to that, teachers also referred to the importance of the Research and Advisory Team in making feasible and realistic suggestions and being flexible during the development of the teachers' action plans.

They [Research and Advisory Team) spent time working with us, drawing suggestions which were grounded on effectiveness factors...which were realistic and feasible.

(Teacher 4)

The team was really helpful...they acknowledged that there isn't such a thing as a perfect action plan and emphasized that it is not the number of actions but the quality that could make a difference. So, we kept it simple, few suggestions and actions... which was something far more convenient for us.

(Teacher 9)

Another important role of the Research and Advisory Team identified by the teachers was related with directing the development of their school's policy / improvement initiative towards important aspects that could indeed improve student learning. 
...what we did, our efforts to improve teaching and learning were backed up from research findings... with reference to what was found to work in relation to improving student outcomes.

(Teacher 1)

In the past we were involved in a number of initiatives which are intellectually superficial and didn't take into account the knowledge base of effective teaching and how teachers could better learn and implement such practices

(Teacher 7)

Another characteristic that the majority of the teachers mentioned as facilitating the effective implementation of DASI at their school was the provision of support, constructive feedback and support by the DASI Research and Advisory Team during the implementation phase. As teachers noted:

...they coordinated the development of our school policy and actions, encouraging our professional growth with respect to teaching methods and collegial interaction about teaching and learning

(Teacher 8)

Members of the research team were regularly visiting our school, providing encouragement and feedback.... inviting us [the school teachers] to observe other teachers while teaching and were emphasizing that everyone has potential for improvement

(Teacher 13)

Their suggestions were always positive, to the point and constructive. They were never too vague, nor negative. I also appreciate the fact that they didn't imposed anything to me, they were offering several choices, and I was expected to follow the choice that was best suited in my teaching style and the ability level of my students

(Teacher 16)

DASI supports that the advisory and research team responsible for the coordination and the general provision of the school improvement program, has an important role in facilitating and supporting teachers in their efforts to develop and implement their action plans in their classrooms / school. Although each teacher is treated as a professional responsible for designing his/her own action plan and implementing his/her own improvement strategies, teachers are not left alone to design and implement their strategies and actions, but are 
encouraged to make use of the expertise and knowledge of the research and advisory team and any other available resource within and/or outside the school. The role of this team for the DASI to succeed was essential, as teachers themselves noted:

Because we had so many administration tasks during the year, they kept on reminding us in our meetings of our primary objective as teachers. And they encouraged us to continue and enhance our efforts for improvement

(Teacher 3)

It was clear that the research team acted as our mentor and coach throughout the school year....at last we had some consultants who understood the real meaning of teaching and provided helpful and constructive feedback

(Teacher 10)

They kept asked us questions about why do we do what we do and what is our ultimate objective while teaching or interacting with children...

(Teacher 12)

Some teachers also considered the role of the research and advisory team as exercising some control which was perceived as a positive drive for teachers to continue their improvement efforts. For example, teacher 4 noted that: "I felt that I had to comply with and follow my action plan in order to improve my teaching. For example, as I've said, to improve the quality and the quantity of the written feedback I was providing to my students, even though I never realised really how this occurred,... it just happened, most probably because I knew that somebody was paying attention to that". And another teacher noted:

I appreciate the fact that they were always starting by emphasizing my strong points, what they liked and why. At the same time they were indicating issues that could be further improved, explaining why and how my practice could be improved and overall helping us to acknowledge the problem....they were making suggestions that were feasible and realistic, given the context I have already described.

(Teacher 5)

According to DASI teachers are the ones to take decisions relating to the improvement actions and tasks to be designed and implemented for their school to improve. By doing so, 
not only is ownership of the improvement effort established, but the teachers` experiences and the context of the school and classroom are also taken into account (Antoniou et al., 2016). At the same time, the Research and Advisory Team has an important role to play in designing teachers' improvement strategies. This team is expected to share its expertise and knowledge with practitioners and help them develop strategies and action plans that are in line with the relevant knowledge base of effective teaching (Creemers \& Kyriakides, 2012). To foster such discussions, the research and advisory team must help teachers to establish trust, develop communication norms that enable critical dialogue, and maintain a balance between respecting individual community members and critically analysing issues in the functioning of effectiveness factors at their school.

\section{3) Evaluation of results and provision of feedback}

Teachers also considered that the evaluation of their effort in relation to student achievement in mathematics was an important facilitator to the school improvement initiative. As our respondents argued, without class- and school-based data about learning, specifically valueadded measurements on student learning, teachers cannot properly determine the effects of what they do in classrooms. It was also stressed that especially in cases where they were assigned to classes with low achievement levels, the evaluation results could help not only to identify the particular attainment levels of the students, but also to demonstrate the difficulties they had to overcome during the academic year and ultimately the progress their students had made by the end of the school year. It was a rather surprising finding of this study, given the context of the English educational system that many teachers were beginning to demonstrate a particular interest in the effectiveness of their improvement efforts. As teachers supported: 
The fact that we would have the chance to see and discuss our students' progress in mathematics was an important factor. We regularly have discussion on why monitoring student progress is so important, as a process which involves interpreting our student assessment data to meet our student individual learning needs, but this is never done to the best possible extent, given the time constraints and the number of students in our classes.

(Teacher 2)

Getting to see the improvement we made as a school in Maths, such kind of value added data are extremely useful...helping us to raise our expectations for success for all students...

(Teacher 5)

This finding relates to perhaps the greatest criticism of school improvement research, i.e., the lack of a robust evaluation mechanism to identify the impact of school improvement initiatives. Coe (2009) notes that many studies use perceptions of participants, which are likely to be influenced by positive bias, to gauge the success of the intervention. Another weakness evident in school improvement research is the persistent lack of focus on student outcomes (Reynolds, 2001). Studies on school improvement initiatives are often more concerned with the process of change and the production of practical strategies rather than with monitoring whether the improvement initiative had a perceptible impact on student achievement (Sammons, 1996). DASI refers to the importance of conducting summative evaluation in order to identify the impact of the school improvement program on student outcomes. This is important, since despite the number of studies on school improvement and teacher professional development, the majority of these do not measure the impact of different approaches and programmes on student learning outcomes (Cochran-Smith \& Zeichner, 2005; Antoniou \& Kyriakides, 2011). Measuring the short- and the long- term impact of the proposed approach is important since it could help us to investigate the addedvalue of using DASI. The results of summative evaluation are also important for taking decisions on whether a school has developed their practices successfully in relation to a specific effectiveness factor and, thus, need to design new action plans in order to address 
new priorities for improvement. This implies that schools should be continuously involved in improvement efforts in order to enhance their effectiveness status.

\subsection{Barriers constraining the effective implementation of DASI:}

Apart from factors facilitating the effective implementation of DASI, a number of factors were identified as barriers constraining the school improvement effort. In the context of this study, teachers referred to teacher resistance to change and time constraints as factors which made the implementation of DASI more difficult.

\section{1) Resistance to change}

Teachers themselves identified that, especially at the early stages of DASI, a barrier they had to face was related with resistance to change. As teachers argued:

Some colleagues were reluctant to engage with the program, and to a certain extent I can understand this. If everything works smoothly why do we need to be involved in such programs, anyway?

(Teacher 4)

To be honest, at the beginning I wasn't that confident of the DASI benefits. Having a huge workload, I was already trying to keep on top of everything.... and I was wondering really... why do we need to change anything to start with!

(Teacher 11)

Teachers are the key actors within schools (Antoniou, 2012). As such it is not surprising that numerous research studies have indicated that, at the classroom level, teachers have the greatest impact on student achievement (Antoniou \& Kyriakides, 2011; 2013). For these reasons, the brunt of work in school improvement initiatives often falls to the teachers. Research indicates that if the teaching staff in the school does not support the initiative, the impact and sustainability of the effects of school improvement are quite low (Hanushek \& Rivkin, 2007). Due to such findings, teacher resistance is a popular topic in school 
improvement literature (Knight, 2009). As Creemers and Reezigt (2005) argue, schools do not change if the people within the schools, particularly the teaching staff, do not change. It is also interesting to note that some teachers decided not to engage with DASI. As teachers noted:

It's really hard to convince everyone... and although [the Research and Advisory Team] tried really hard, was flexible with practical and feasible suggestions, some colleagues will still refuge to follow

(Teacher 11)

....and we had a couple of cases which they remained neutral throughout the year. For example, [name of teacher] was negative from the very beginning and retained a rather passive role in the improvement effort throughout the year...

(Teacher 15)

Preparation and willingness to engage in the process are also key when it comes to interdisciplinary collaboration within school improvement initiatives. Research on school consultation indicates that multi-professional interactions between school personnel and nonteacher consultants is often challenging (Thornberg, 2014). Rubinson (2002) found that teachers prefer to seek advice from their school peers rather than from individuals from outside their profession. Thornberg (2014) suggests that teachers and consultants may struggle to successfully collaborate due to the different goals and purposes, associated with their select professions. In one study, teachers tended to disengage from the intervention process because of the incongruence between their practice and beliefs, and the approach taken by the intervention team (Slonski-Fowler \& Truscott, 2004). This indicates that school improvement will not succeed simply due to the presence of outside specialists; professional boundaries and collaboration needs to be addressed prior to the implementation of improvement initiatives.

\section{2) Time constraints}


Another constraint identified by the majority of the teachers was related with lack of time. However, teachers acknowledged at the same time the important role of the Research and Advisory Team, in making the most of their time as has been discussed earlier. As teachers mentioned:

We are asked to do and we are responsible for so many things nowadays, from preparing lesson plans and handouts to marking and decorating our classroom, which simply leaves us very little time to engage with the initiative to the desired extent. I personally took time out of my personal time to reflect and revise my action plan. This of course, proved to be beneficial at the end.

(Teacher 8)

Although we would like to spend even more time on discussing our action plans and our school policy, what worked and why and what others have done, this was not possible due to a lack of resources and a tight budget to buy-in replacements or to subsidise the time for school improvement.

(Teacher 12)

In recent years, teachers' roles have diversified, thus increasing the average teacher's workload quite significantly (Gu \& Day, 2013). In addition to teaching class, teachers are required to mark, plan lessons, attend meetings, contact parents, engage in an array of supervision duties, organize clubs, participate in sporting events, compile reports and so on, on a day to day basis (Knight, 2009, p. 509). Due to the daily "press of immediacy", teachers may struggle to find time to engage with and implement school improvement initiatives (Knight, 2009). A number of studies (e.g., Chapman \& Harris, 2004; Mendenhall et al. (2013); Rhodes \& Houghton-Hill, 2000) found lack of time to be a factor the teaching staff noted as a barrier when it came to practical application of school reform. Mendenhall, Iachini and Anderson-Butcher (2013) reported that the teachers in their sample were unpleasantly surprised by the amount of time the improvement initiative took out of their already busy schedule. Similarly, Rhodes and Houghton-Hill, (2000) identified busy work schedule and shortage of time, as one of the key reasons teachers were not open to engaging in school improvement initiatives. This finding does not stand alone, as a cross-cultural survey, sited by 
Jošić, Džinović, and Ćirović, (2014) showed that $47 \%$ of teachers indicated absence of time to be a challenge in the work place, which prevented them from engaging in professional development or additional initiatives in their schools. On the basis of these findings, the authors, in their concluding remarks, theorized that it is possible some school improvement projects fail because teachers simply do not have enough time to apply the initiatives completely and as they are intended. As such, it is important to consider the effect this barrier has on the success of school improvement initiatives, because even the least intrusive approach will increase the level of work and decrease the amount of time available to the teaching staff.

\section{Conclusion}

This exploratory case study provided an in-depth understanding of the teachers' perspectives of implementing the DASI framework, exploring the types of challenges and facilitators experienced by teachers in the process of implementing DASI in a primary school in England with a relatively high percentage of socially disadvantaged students during the academic year 2015-2016. According to a report by the Social Mobility and Child Poverty Commission of the UK government (2016), many of the richest places in England, like Worcester, Northampton, Cambridge and Oxford are doing worse than places that are much poorer and are actually among the worst-performing $20 \%$ of areas in terms of equity and social mobility. 
A number of studies, usually experimental, employing quantitative methodology, have validated the DASI framework and revealed that this approach could have a positive impact on primary students' academic outcomes (Creemers, Kyriakides \& Antoniou, 2013b). Nevertheless, more research on the DASI framework is necessary as the framework has not been studied extensively through qualitative studies and especially in relation to whether it could be used to improve both quality and equity in education. This is also related with a criticism of educational effectiveness research in that the findings of school effectiveness research tend to judge schools in a binary manner as either effective or not, without necessarily explaining how and under which conditions schools could improve their effectiveness status (Scheerens, 2015; Reynolds, 2001).

Based on the research findings, teachers have identified a number of facilitators situated at various levels. At the teacher level, related with teacher characteristics, teacher efficacy and teacher engagement and commitment have been identified. At the school level, teachers identified two other factors related with supportive school leadership and collaboration between peers. Finally, a number of facilitators have been identified at the DASI level. Those were related with (a) clarity of objectives, (b) the role of the Research and Advisory Team, and (c) evaluation of results and provision of feedback. In addition to facilitators, teachers identified resistance to change and time constraints as challenges that they encountered in the course of implementing DASI. A common element in all teacher interviews was related with the important role of the Research and Advisory Team which facilitated to a great extent the effective implementation of DASI by providing a clear focus / objectives based on evaluation data, providing feasible and realistic suggestions, respecting teachers' time, retaining balance between feedback, support and control, and being flexible acknowledging that themselves were in a learning process along with the school staff. 
The findings of this study are in line with previous research findings on school improvement (Chapman \& Harris, 2004; Gu \& Day, 2013; Mendenhall et al., 2013; Jošić, Džinović \& Ćirović, 2014; Rhodes \& Houghton-Hill, 2000; Hakanen et al., 2006). However, several studies place the brunt of the blame on teachers in case of reform failure, and discuss strategies to overcome teacher resistance (Knight, 2009). We argue that such a perspective only considers the symptoms, rather than examining the roots of the problem. Relatively few studies have considered the obstacles teaching staff experiences in the process of implementing school improvement approaches. Teachers have a unique perspective on school reform since they bear the brunt of the work in such projects. Therefore, their perceptions and experiences should be considered and addressed prior to the implementation of improvement initiatives.

The existing literature on school improvement does not adequately indicate what works and why, meaning that it is still largely unknown why some school improvement initiatives are successful while others fail. In this paper, we argue that there are always going to be challenges, constraints and barriers to any school improvement initiative. The decisive point for any school improvement initiative is to present a number of facilitators which could overweight the barriers and could help teachers and schools to actively engage with the improvement process.

We need to acknowledge, however, that the use of an evidence-based and theorydriven framework, such as DASI, on the basis of which the content of the school improvement program is to be selected and formulated, cannot in itself ensure that the programme will be effective for all schools. DASI supports that not only should a theorydriven approach be followed to improve quality of teaching, but emphasis should also be placed on collecting data in order to identify needs and priorities for improvement for different schools, thereby facilitating the design of relevant improvement efforts with 
differentiated content and focus. This is important, since teachers seem to consider new initiatives on their individual merits, particularly in relation to how they will benefit classroom teaching in their own professional context (Corkindale \& Trorey, 2002). Teachers have turned away from various school improvement approaches, which are not seen to have ready relevance to and application in, the classroom and are not geared to teachers' needs (Dinham et al., 2000). Thus, DASI is neither based on improvement prescriptions or predetermined requirements for teachers to follow in order to improve their skills, nor on relying solely on teachers to identify by themselves what can be done and how in order to improve the quality of their teaching. DASI provides teachers the opportunity to identify their improvement needs and make use of the available knowledge-base in order to develop their action plans and critically reflect on their efforts in order to improve their teaching skills.

The research reported here, is based on a qualitative methodological design. The fundamental purpose was to explore the barriers and facilitators to school improvement, with an emphasis on both quality and equity issues, based on teacher perceptions. In this perspective the results cannot be generalized to all schools and teachers in England. It was not the scope of this study to identify the impact and impose control over conditions and variables that could affect the true effects of the DASI upon any dependent variables, such as student outcomes. Another limitation of the study relates with the length of the intervention. According to research findings, any intervention needs to be implemented for more than a year's time in order for any kind of impact to be detectable (Sammons, 2006; Teddlie \& Reynolds, 2000). To deal with this issue we have made clear to the participants that the program will go on for at least one more year and that their participation for a second consecutive year is important for the study.

Suggestions for future research could also be drawn. Particularly, future research could employ experimental designs to compare the effectiveness of different school 
improvement initiatives, considering the barriers identified in this study. Such studies could also investigate the functioning of school factors and their impact on quality of teaching. In addition, taking into consideration that school leadership is of great importance to any educational activity (Antoniou, 2013), future studies could reveal the extent to which school leadership contributes to the effective implementation of school improvement initiatives, and may also help us identify the various forms by which school principals perform their role as instructional leaders (Heck \& Hallinger, 2005). Moreover, although in this study the implementation of the DASI was for a one year period, it is necessary to investigate both the barriers and facilitators and the effects of the program in extended time periods. Longitudinal studies which expand for more than a years' time could reveal the long-term effect of the intervention and the sustainability of the effect. In addition, more studies could be conducted in different countries illustrating how the Dynamic Approach can be used by policy and practice for school improvement with an emphasis on quality and equity issues. Moreover, more studies should be conducted in order to establish further links between Educational effectiveness research (EER) and research on school improvement. By establishing links between these two fields, both of them could have mutual benefits. Particularly, research on school improvement could expand its research agenda by taking into consideration the impact of effective programs on student outcomes and at the same time EER could identify the extent to which its theoretical models could be used for improvement purposes. In this way, stronger links between research, policy and improvement of teaching practice could be established. The results of such studies may also contribute to the further development of the framework related to the use of the dynamic model for improvement purposes and also to the establishment of a theory-driven and evidence-based approach to improving the quality of teaching. 
In this study, we build on and extend the work of those who advocate a more dynamic understanding of school improvement in an attempt to conceptualize this complex process in ways that provide a foundation for future empirical work. We rely on a complexity theory orientation that could facilitate our understanding of dynamics both within and across different levels, such as the teacher, the school and the improvement approach levels and the ways these levels interact, resulting in the emergence of school improvement. This is turn could enhance our understanding of the conditions under which the DASI is implemented most effectively and provide suggestions for schools going through similar school improvement - reform initiatives. 


\section{References}

Antoniou, P.,Louw, J., \& Gronn, P. (2016). School Self-Evaluation for School Improvement. Examining the Measuring Properties of the LEAD Surveys. Australian Journal of Education. 60 (3), 191-210.

Antoniou, P., Kyriakides, L. \& Creemers, B.P.M (2015). A Dynamic Integrated Approach to Teacher Professional Development. Rationale and Main Characteristics. Teacher Development. 19 (4), 535 - 552.

Antoniou, P. \& Kyriakides, L. (2013). A Dynamic Integrated Approach to Teacher Professional Development: Impact and Sustainability of the Effects on Improving Teacher Behavior and Student Outcomes. Teaching and Teacher Education, 29 (1), 112.

Antoniou, P. (2013). Development of Research on School Leadership Through Evidencebased and Theory Driven Approaches: A Review of School Leadership Effects Revisited. School Effectiveness and School Improvement, 24 (1),122-128.

Antoniou, P. (2012). The Short- and Long- term Effects of Secondary Schools upon Students' Academic Success and Development. Educational Research and Evaluation, 18 (7), $621-640$.

Antoniou, P. \& Kyriakides, L. (2011). The Impact of a Dynamic Approach to Professional Development on Teacher Instruction and Student Learning: Results from an Experimental Study. School Effectiveness and School Improvement, 22 (3), 291 - 311.

Blumer, H. (1969). Symbolic interactionism: Perspective and method. Englewood Cliffs, NJ: Prentice Hall.

Borman, G.D., Hewes, G.M., Overman, L.T., \& Brown, S. (2003). Comprehensive school 
reform and achievement: A meta-analysis. Review of Educational Research, 73, 125230.

Chapman, C, Muijs, D, Reynolds, D, Sammons, P, Teddlie, C. (2015). The Routledge International Handbook of Educational Effectiveness and Improvement: Research, policy, and practice. DOI: http://dx.doi.org/10.4324/9781315679488

Chapman, C, Armstrong, P, Harris, A, Muijs, D, Reynolds, D, Sammons, P. (2012). School effectiveness and improvement research, policy, and practice: Challenging the orthodoxy? DOI: http://dx.doi.org/10.4324/9780203136553

Chapman, C. and Harris, A. (2004). Strategies for School Improvement in Schools facing Challenging Circumstances. Educational Research, Vol. 46(3), 119-228.

Cochran-Smith, M., \& Zeichner, M. K. (2005). Studying teacher education: The report of the AERA Panel on Research and Teacher Education. AERA Panel on Research and Teacher Education. Routledge.

Coe, R. (2009). School improvement: Reality and illusion. British Journal of Education Studies, 57(4), 363-379.

Corkindale, J., \& Trorey, G. (2002). Career Dynamics in Further and Higher Education. In G. Trorey, \& C. Cullingford (Eds), Professional Development and Institutional needs (pp.79-101). Hampshire, England: Ashgate Publishing.

Cornford, I.R. (2002). Reflective teaching: Empirical research findings and some implications for teacher education. Journal of Vocational Education \& Training, 54, 219-236.

Creemers, B.P.M., \& Kyriakides, L. (2015). Developing, testing and using theoretical models of educational effectiveness for promoting quality in education. School Effectiveness and School Improvement, 26 (1), 102-119. 
Creemers B.P.M., \& Reezigt J.G. (2005). Linking School Effectiveness and School Improvement: The background and outline of the project. School Effectiveness and School Improvement, 16 (4), 359-371.

Creemers, B. P. M., \& Kyriakides, L. (2008). The dynamics of educational effectiveness: A contribution to policy, practice, and theory in contemporary schools. London: Routeledge.

Creemers, B. P. M., \& Kyriakides, L. (2010a). School factors explaining achievement on cognitive and affective outcomes: Establishing a dynamic model of educational effectiveness. Scandinavian Journal of Educational Research, 54(3), 263-294.

Creemers, B. P. M., \& Kyriakides, L. (2010b). Using the dynamic model to develop an evidence-based and theory-driven approach to school improvement. Irish Educational Studies, 29, 5-23.

Creemers, B. P. M., Kyriakides, L., \& Sammons, P. (2010). Methodological Advances in Educational Effectiveness Research. London and New York: Taylor \& Francis.

Creemers, B. P. M., Kyriakides, L. (2012). Improving Quality in Education: Dynamic Approaches to School Improvement. Abingdon, Oxon: Routledge.

Creemers, B. P. M., Kyriakides, L. \& Antoniou, P. (2013a). Teacher Professional Development for Improving Quality of Teaching. London: Springer.

Creemers, B. P. M., Kyriakides, L. \& Antoniou, P. (2013b). A dynamic approach to school improvement: Main features and impact. School Leadership \& Management, 33(2), $114-132$.

Creswell, J. W. (2012). Educational research: Planning, conducting, and evaluating quantitative and qualitative research. Boston, Mass.: Pearson.

Creswell, J. W., \& Plano Clark, V. K. (2011). Designing and Conducting Mixed Methods Research (2 $2^{\text {nd }}$, edn.). Thousand Oaks, California: Sage Publications Inc. 
Dinham, S., Brennan, K., Collier, J., Deece, A., \& Mulford, D. (2000). The Secondary Head of Department: Key Link in the Quality Teaching and Learning Chain. Quality Teaching Series, 2, 1-35.

Fidler, B. (2001). A structural critique of school effectiveness and school improvement. In A. Harris, \& N. Bennett, (Eds.), School effectiveness and school improvement: Alternative perspectives. (pp. 48-74) London: Continuum.

Garet, M.S., Porter, A.C., Desimone, L., Birman, P.F., \& Yoon, K.S. (2001). What makes professional development effective? Results from a national sample of teachers. American Educational Research Journal, 38(4), 915-945.

Gray, J. (2000). Causing concern but improving: A review of schools' experiences. London: Department for Education and Skills.

Glazer, B.G. (1965). The constant comparative method of qualitative analysis. Social Problems. 12, 436-445.

Glaser, B.G. \& Strauss, A. (1967). Discovery of Grounded Theory. Strategies for Qualitative Research. Sociology Press.

Gu, Q., \& Day, C. (2013). Challenges to teacher resilience: Conditions count. British Educational Research Journal 39(1), 22-44.

Hattie, J. (2009). Visible learning: A synthesis of over 800 meta-analyses relating to achievement. New York: Routledge.

Hakanen, J. J., Bakker, A. B., \& Schaufeli, W. B. (2006). Burnout and work engagement among teachers. Journal of School Psychology, 43(6), 495-513. doi:10.1016/j.jsp.2005.11.001.

Halbesleben, J. (2010). A meta-analysis of work engagement: Relationships with burnout, 
demands, resources, and consequences. In A. B. Bakker, \& M. P. Leiter (Eds.), Work engagement. A handbook of essential theory and research (pp. 102-117). New York: Psychology Press.

Hallinger, P. \& Heck, R. H. (2011). Conceptual and methodological issues in studying school leadership effects as a reciprocal process. School Effectiveness and School Improvement, 22(2), 1-27.

Hanushek, E. A., \& Rivkin, S. G. (2007). Pay, working conditions and teacher quality. The Future of Children, 17(1), 69-86.

Heck, R. H., \& Moriyama, K. (2010). Examining relationships among elementary schools' contexts, leadership, instructional practices, and added-year outcomes: a regression discontinuity approach. School Effectiveness and School Improvement, 21(4), 377408.

Heck, R.H., \& Hallinger, P. (2005). The Study of Educational Leadership and Management Where Does the Field Stand Today? Educational Management Administration \& Leadership 33 (2), 229-244

Hopkins, D., Ainscow, M. \& West, M. (1994). School Improvement in an Era of Change. London: Cassell.

Hoy, W. K., \& Hannum, J. W. (1997). Middle school climate: An empirical assessment of organizational health and student achievement. Educational Administration Quarterly, 33, 290-311.

Jošić, S., Džinović, V., \& Ćirović, I. (2014). Teachers’ perceptions of factors impeding school improvement in Serbia. Psihologija, 47(2), 231-247.

Knight, J. (2009). What can we do about teacher resistance? Phi Delta Kappan, 90, 508-513.

Kirkpatrick, C. L., \& Johnson, S. M. (2014). Ensuring the ongoing engagement of second- 
stage teachers. Journal of Educational Change, 15, 231-252.

Kyriakides, L. \& Creemers, B. P. M. (2008). Using a multidimensional approach to measure the impact of classroom-level factors upon student achievement: A study testing the validity of the dynamic model. School Effectiveness and School Improvement, 19(2), 183-205.

Kyriakides, L., Creemers, B. P. M., \& Antoniou, P. (2009). Teacher behaviour and student outcomes: Suggestions for research on teacher training and professional development. Teaching and Teacher Education, 25(1), 12-23.

Lawless, A.K. \& Pellegrino, W.J. (2007). Professional Development in Integrating technology into teaching and learning: Knowns, unknowns and ways to pursue better questions and answers. Review of Educational Research, 77 (4), 575-614.

Macey, W. H., Schneider, B., Barbara, K. M., \& Young, S. A. (2009). Employee engagement: Tools for analysis, practice and competitive advantage. Malden, MA: Wiley.

Mendenhall, A. N., Iachini, A., \& Anderson-Butcher, D. (2013). Exploring stakeholder perceptions of facilitators and barriers to implementation of an expanded school improvement model. Children \& School, 35(4), 225-234.

Muijs, D., Harris, A., Chapman, C., Stoll, L. \& Russ, J. (2004). Improving Schools in Socioeconomically Disadvantaged Areas - A Review of Research Evidence. School Effectiveness and School Improvement, 5 (2), 49-175.

National Center on Effective Secondary Schools. (1992). In F. M. Newmann (Ed.), Student engagement and achievement in American secondary schools [microform]. Washington, DC: ERIC Clearinghouse. Retrieved from http://www.eric.ed.gov/contentdelivery/servlet/ERICServlet?accno=ED371047.

Pas, E. T., Bradshaw, C. P., \& Hershfeldt, P. A. (2012). Teacher- and school-level predictors 
of teacher efficacy and burnout: Identifying potential areas for support. Journal of School Psychology, 50, 129-145.

Reynolds, D., Sammons, P., De Fraine, B., Van Damme, J., Townsend, T., Teddlie, C., et al. (2014). Educational effectiveness research (EER): a state-of-the-art review. School Effectiveness and School Improvement, 25(2), 197e230.

Reynolds, D. (2001). Beyond school effectiveness and school improvement. In A. Harris, \& N. Bennett, (Eds.), School effectiveness and school improvement: Alternative perspectives. (pp. 26-43) London: Continuum.

Rhodes, C., \& Houghton-Hill, S. (2000). The Linkage of Continuing Professional Development and the Classroom Experience of Pupils: barriers perceived by senior managers in some secondary schools. Journal of In-Service Education, 26(3), 423435.

Rubinson, F. (2002). Lessons learned from implementing problem-solving teams in urban high schools. Journal of Educational and Psychological Consultation, 13, 185-217. Sammons, P. (2006). Embracing Diversity: New challenges for School Improvement in a Global Learning Society. Keynote speech at International Congress for School Effectiveness and Improvement, Fort Lauderdale: Florida 4th January 2006.

Sammons, P. (1996). Complexities in the Judgement of School Effectiveness. Educational Research and Evaluation, 2 (2) 113 - 149.

Scheerens, J. (2016). Educational Effectiveness and Ineffectiveness. A Critical Review of the Knowledge Base. London: Springer publishing.

Scheerens, J. (2015). Theories on educational effectiveness and ineffectiveness. School Effectiveness and School Improvement, 26 (1), 10-31. 
Strand, S. (2014). Ethnicity, gender, social class and achievement gaps at age 16: intersectionality and 'getting it' for the white working class", Research Papers in Education, 29 (2), 131-171.

Slonski-Fowler, K. E., \& Truscott, S. D. (2004). General education teachers' perceptions of the prereferral intervention team process. Journal of Educational and Psychological Consultation, 15, 1-39.

Smith,M. S.,\& O'Day, J. (1991). Systemic school reform. In S. Fuhrman,\&B. Malen (Eds.), The politics of curriculum and testing (pp. 233e268). Philadelphia: Falmer Press.

Social Mobility and Child Poverty Commission (2016), Report on England's new geography of disadvantage, accessed online on October 2016, from https://www.gov.uk/government/news/kids-education-and-employment-opportunitiesranked-by-area.

Sprinthall, N., Reiman, A., \& Thies-Sprinthall, L. (1996). Teacher professional development. In J. Sikula, T. Buttery, \& E. Guyton (Eds.), Handbook of research on teacher education (2nd ed., pp. 666-703). New York: Macmillan.

Tashakkori, A. \& Teddlie, C. (1998). Mixed Methodology: Combining Qualitative and Quantitative Approaches. Thousand Oaks, California: SAGE Publications Ltd. Teddlie, C. \& Sammons, P. (2010). Applications of mixed methods to the field of Educational Effectiveness Research. In Creemers, B.P.M., Kyriakides, L., \& Sammons, P. (Eds). Methodological Advances in Educational Effectiveness Research, p. 115 -152, Routledge: London and New York. \#

Teddlie, C., \& Reynolds, D., (2000). The International Handbook of School Effectiveness Research. London: Falmer Press.

Thornberg, R. (2014). Consultation barriers between teachers and external consultants: A 
grounded theory of change resistance in school consultation. Journal of Educational and Psychological Consolation, 24, 183-210.

Wayne, A. J., Kwang S. Y., Pei Zhu, Stephanie C., \& Michael S. Garet (2008).

Experimenting with Teacher Professional Development: Motives and Methods.

Educational Researcher 37(8), 469-479. 